\title{
FORMAÇÃO CONTINUADA DE PROFESSORES DA EDUCAÇÃO PROFISSIONAL'
}

http://dx.doi.org/10.5902/2176217110500

\author{
Ana Sara Castaman \\ Instituto Federal de Educação, Ciência e Tecnologia do \\ Rio Grande do Sul - campus Sertão, Brasil. \\ Marilandi Maria Mascarello Vieira \\ Instituto Federal de Educação, Ciência e Tecnologia do \\ Rio Grande do Sul - campus Sertão, Brasil.
}

\begin{abstract}
Resumo
O artigo relata uma experiência de formação pedagógica realizada em 2012 com docentes da educação profissional de uma instituição federal. Os dados empíricos foram coletados por meio de relatos dos participantes durante o curso e enfocam a importância da formação continuada para docentes que não tiveram formação pedagógica em seus cursos superiores, bem como a contribuição para o processo ensino e aprendizagem. Conclui-se que a formação continuada contribuiu para reflexões colaborativas entre os docentes e no seu fazer cotidiano.

Palavras-chave: formação continuada de professores, processo ensino e aprendizagem, educação profissional.
\end{abstract}

\section{CONTINUING EDUCATION TEACHER EDUCATION PROFESSIONAL}

\section{Abstract}

The paper reports an experience of teacher training held in 2012 with teachers of vocational education in a federal institution. The empirical data in this article were collected through accounts of the participants during the course and focus on the importance of continuing education for teachers who have not had training in teaching their courses and higher contribution to the teaching and learning process. Concludes-if that the continued formation contributed to reflections collaborative among faculty and on your to do quotidian.

Key-words: continuing education for teachers, process teaching and learning, professional education.

1 Esse texto, com algumas modificações, foi apresentado no III Seminário Internacional de Gestão Educacional e VI Semana do curso de Especialização em Gestão Educacional da UFSM .

Regae: Rev. Gest Aval Educ.

p. $7-15$ 


\section{Introdução}

A crença de que a formação pedagógica é um requisito essencial apenas para os profissionais que atuam com crianças, relegando esse aspecto a segundo plano quando se trata do ensino de adultos, faz parte da cultura educacional, mas vem sendo alterada, pois as mudanças no mundo do trabalho exigem um perfil diferente de trabalhador educacional, que, por sua vez, deve buscar ser polivalente, criativo, pró-ativo, entre outras características que compõem o perfil deste profissional.

Cristóvam Buarque (2003, p. 25) acredita que não ocorreram grandes mudanças estruturais nas instituições de ensino nos últimos mil anos, porém, o mundo, em termos de informação, conhecimento e novas técnicas de comunicação teve grandes transformações. Isso exige que os estudantes tenham a capacidade de renovar, e não sair da universidade com um conjunto de conhecimentos duradouros, pois eles se tornam obsoletos com muita rapidez. Noutras palavras, a docência, mais do que transmitir conhecimentos prontos, se constitui no desafio de formar sujeitos pensantes, criativos, capazes de lidar com o novo, de transferir recursos conceituais e procedimentais, que Ihes permitam criar soluções para os desafios que se manifestam. Existe, portanto, a exigência de docentes cujo perfil contemple saberes específicos da área em que atuam, mas também a sensibilidade para disponibilizá-los adequadamente e despertar nos alunos o interesse pela busca do conhecimento.

A docência nos cursos técnicos tem sido exercida por profissionais de diferentes áreas do conhecimento e com diferentes tempos de dedicação à instituição onde atuam. Alguns deles nunca tiveram contato com a formação pedagógica sistemática, pois como afirma Oliveira (2006), o professor do ensino técnico não é concebido como profissional da educação, mas um profissional de outra área e que nela também leciona. No entanto, atualmente não basta ter competência técnica, domínio de conteúdo e a titulação compatível com a função ou ser um profissional de renome no mercado de trabalho para legitimar-se como professor.

Diante da especificidade da docência na contemporaneidade, os saberes necessários à profissão são objeto de estudo por diferentes autores. Para Saviani (1996) os saberes pedagógicos são os conhecimentos produzidos pelas ciências da educação e sintetizados nas teorias educacionais, que tem por escopo articular os fundamentos da educação com as orientações que se imprimem ao trabalho. Na sua concepção, são esses os saberes que distinguem o profissional da educação dos demais profissionais "que dão aulas", pois esse tipo de saber fornece a base de construção da perspectiva especificamente educativa com base na qual se define a identidade do educador como um profissional

Nesse sentido a formação continuada é considerada essencial a profissionais que trabalham com a mudança, construção, incertezas, exigindo flexibilidade e habilidade de lidar com o inédito na ação cotidiana.

Os conhecimentos procedimentais e as relações interpessoais, elementos essenciais na prática docente, nem sempre recebem a atenção necessária e alguns profissionais pouco se questionavam sobre como o aluno aprende.

Estudos indicam que quando o profissional não tem formação pedagógica, a sua prática normalmente reflete a postura dos professores que atuaram na sua formação. 
Alguns tornam-se autodidatas e superam dificuldades movidos pelo entusiasmo da profissão e outros aprendem por erros e acertos. Há também os que só buscam a preparação pedagógica quando se deparam com situações desafiadoras na sala de aula.

Nos últimos anos, observamos a ampliação do acesso aos cursos de educação profissional, especialmente a partir da criação dos Institutos Federais de Educação, fato que traz como aspecto altamente positivo a democratização das oportunidades educacionais, mas que revela fragilidades na formação de estudantes que enfrentam um processo de seleção menos rigoroso em muitos cursos e ingressam nessas instituições educacionais com menor capital cultural. A soma desses fatores aponta para a necessidade de formação pedagógica.

Por outro lado, a invasão da tecnologia digital está transformando ambientes tradicionais de ensino, já que os estudantes são nativos digitais que, dominando a tecnologia, têm acesso a uma rede quase infinita de informações e de interações até então inimagináveis.

Essa situação gera um novo perfil de aluno, cada vez mais estimulado pelas informações, capaz de realizar simultaneamente múltiplas tarefas e com disposição permanente para interagir com o conteúdo apresentado. O seu processamento de informações, antes focal e com memória maior, agora é tipicamente multifocal e, em contrapartida, com menor capacidade mnemônica.

Esse novo perfil de aluno exige, por sua vez, alterações no processo educativo, quer em termos de estrutura física e acesso a equipamentos, quer na formação dos professores e na formulação das práticas pedagógicas, pois, tendo crescido no mundo interativo da Internet, não vê mais sentido em aulas tradicionais que ocorriam há vinte anos. O reconhecimento da heterogeneidade em salas de aula também ganha ênfase, fomentando a reflexão de que as metodologias de ensino repercutem diferentemente em uma mesma turma.

As inovações pedagógicas, portanto, podem resultar em tensões e não meramente na inserção de novidades técnicas e tecnológicas ou modernizações gratuitas e podemos salientar que os momentos de crise, de contradição, podem impulsionar mudanças positivas ou resistências importantes. Para tanto, é necessária a formação continuada e o acompanhamento permanente dos profissionais da educação. Apesar de ainda haver resistências no que se refere à capacitação pedagógica, as discussões sobre o tema no meio acadêmico estão cada vez mais intensas e surgem relatos de experiências exitosas.

Com o intuito de oportunizar formação profissional docente e fomentar inovações pedagógicas, o Núcleo de Apoio Psicopedagógico e Educacional, junto com o curso de Pedagogia do Instituto Federal Catarinense - Campus Videira, disponibilizam curso de Formação Continuada em Metodologias de Ensino e Aprendizagem aos docentes dos cursos técnicos em Segurança do Trabalho e Eletroeletrônica, o qual consistiu no conhecimento e vivência de estratégias de trabalho docente, com o intuito de que tivessem caráter facilitador do processo de ensino e aprendizagem.

O objetivo do referido curso foi que os docentes compreendessem os processos de ensino e aprendizagem e suas características, bem como as suas implicações para o trabalho docente. Ainda, visou-se o reconhecimento da relevância e dos componentes do plano de ensino; conhecimento das regras básicas para elaboração de instrumentos de avaliação; identificação de estratégias de ensino e seleção das mais compatíveis com a 
disciplina e objetivos a alcançar e por fim, a reflexão sobre as principais concepções de aprendizagem, relacionando-as às estratégias de ensino e avaliação.

Neste trabalho analisa-se como aquela experiência de formação pedagógica, segundo os docentes participantes, tem facilitado o processo ensino e aprendizagem e a importância da formação para o cotidiano da sala de aula. No primeiro momento apresenta-se a metodologia empregada, após discorre-se sobre a importância da formação continuada para docentes da educação profissional e, por fim como a formação continuada pode facilitar o processo ensino e aprendizagem.

\section{Metodologia}

A atividade foi realizada no primeiro semestre de 2012 no Instituto Federal Catarinense - Campus Videira, localizado na região meio oeste catarinense. O IFC Videira iniciou suas atividades em março de 2006, como extensão da Escola Agrotécnica Federal de Concórdia, com a primeira turma do Curso de Educação Profissional Técnica de Nível Médio em Agropecuária. Em 2009 iniciaram-se as atividades com estudantes nos cursos de Eletroeletrônica e Informática, e em 2010 o curso Técnico em Segurança do Trabalho.

Atualmente a instituição oferta 12 cursos regulares, sendo seis cursos técnicos nas modalidades integrado, subsequente e concomitante, três cursos superiores e três cursos de pós-graduação em nível de especialização, totalizando 34 turmas, com 1.268 estudantes matriculados, 61 docentes e 57 técnico-administrativos.

O curso de formação foi organizado em encontros mensais que totalizaram 40 horas, coordenados pelas docentes responsáveis pela atividade, ou seja, três docentes do curso de graduação em Pedagogia daquela instituição.

O processo reflexivo pautou-se no estudo dos temas propostos para cada etapa da formação, que foram precedidos pela leitura de textos-base, feita a distância, e da discussão entre os participantes. Além dessa estratégia, também foram realizados seminários, cuja apresentação ficou ao encargo de cada participante, bem como elaboração e análise dos planos de ensino e de instrumentos de avaliação.

Os temas abordados foram o planejamento do processo ensino-aprendizagem, a elaboração dos planos de ensino, orientações para elaboração de instrumentos de avaliação, estratégias de ensino-aprendizagem e concepções de aprendizagem.

Os participantes foram oito docentes dos cursos técnicos em Segurança do Trabalho e de Eletroeletrônica contratados em regime de dedicação exclusiva, com formação profissional na área das engenharias, com idade entre 25 a 32 anos e vivenciando, em sua maioria, as primeiras experiências como docentes.

Também fizeram parte do grupo três técnicas para assuntos educacionais, com vínculo contratual de 40 horas, com formação em cursos de licenciatura e idade entre 25 a 40 anos, que atuam como equipe de apoio aos docentes e estudantes dos referidos cursos. Os excertos analisados no texto provêm de depoimentos e reflexões colhidos durante o processo de formação continuada.

Importância da formação continuada para professores da educação profissional

O panorama evidenciado atualmente na educação profissional brasileira revela a necessidade de uma reestruturação na formação que articule teoria e prática, o científico 
e o tecnológico, com conhecimentos que permitam aos docentes aperfeiçoar a atuação no mundo do trabalho de forma autônoma e com espírito crítico e criativo, pois, como afirma Giesta (2001, p. 412), "ensinar hoje, exige desenvolvimento de habilidades de comunicação, raciocínio, criticidade e criatividade, que não fiquem apenas nas intenções, mas que sejam calcadas no desenvolvimento contínuo e isso passa, pela atualização dos saberes".

Machado (2008, p. 15) assim comenta sobre a formação de professores adequada à atual complexidade do mundo do trabalho:

Os professores de educação profissional enfrentam novos desafios relacionados às mudanças organizacionais que afetam as relações profissionais, aos efeitos das inovações tecnológicas sobre as atividades de trabalho e culturas profissionais, ao novo papel que os sistemas simbólicos desempenham na estruturação do mundo do trabalho, ao aumento das exigências de qualidade na produção e nos serviços, à exigência de maior atenção à justiça social, às questões éticas e de sustentabilidade ambiental. São novas demandas à construção e reconstrução dos saberes e conhecimentos fundamentais à análise, reflexão e intervenções críticas e criativas na atividade de trabalho.

Para além dessa interface de formação, que visa a melhorar o sistema educacional, se entende que esta deve facilitar essas mesmas atitudes para seus alunos, bem como currículo articulado entre a realidade concreta e o conhecimento científico. Porém, muitos cursos profissionalizantes apresentam uma estrutura curricular fragmentada, ou seja, mesmo que em seus projetos pedagógicos tenha um perfil do egresso que vise articular questões teóricas a práticas, ou que sejam conteúdos atualizados e próximos a realidade local e dos alunos, no geral os conteúdos ficam descontextualizados. Para Giesta (2001, p. 411) "a aquisição de informações fragmentadas e dirigidas para a prática minimiza a ação intelectual do professor". A confiança do docente em reconhecer-se apto a compreender e analisar as políticas, procedimentos, resultados, estudos, propostas educacionais "inerentes à sua profissão e qualificação alavanca sua identidade profissional" (Ibid., p. 411) e, com efeito, esse docente se compromete com sua formação inicial e continuada.

Como responsáveis pelo curso de formação continuada partimos da necessidade, expressas pelos participantes, de relacionar o saber com as situações do cotidiano da sala de aula, que a formação fosse pautada numa proposta que facilitasse as intenções e ações dos docentes, e aplicadas a projetos vinculados aos seus estudos ou disciplinas. Assim, pretendeu-se no curso de formação continuada provocar um conjunto das interações e ações que viessem a facilitar a articulação entre os componentes curriculares dos cursos à realidade local dos alunos.

No primeiro encontro do referido curso os docentes relataram as dificuldades enfrentadas na sala de aula, já que a grande maioria havia ingressado recentemente na instituição e iniciava o exercício da profissão docente sem a salvaguarda da formação que Ihe assegure a identidade, o ofício de mestre, como menciona Miguel Arroyo (2000, p. 25): "uso a expressão ofício de mestre para chamar a atenção para essa longa história, para procurar nossa identidade longe, para nos ver como uma construção social, histórica, cultural que finca raízes profundas no passado." 
Os participantes assim expressaram suas angústias, necessidades e expectativas:

Nunca havia estado em uma sala de aula, às vezes tenho dificuldade em mediar os conteúdos aos alunos. Não sei que linguagem utilizar, técnicas, etc. (Professor A)

Tenho uma formação técnica, o que dificulta formar na perspectiva humanística e instrumentalizar os alunos também para serem autônomos e cidadãos. (Professor B)

Precisamos de formação continuada, porque nas engenharias não há disciplinas pedagógicas, didáticas, o que não nos fortalece como docentes. Necessitamos aprender metodologias que facilitem o processo ensino e aprendizagem e aproximem o conteúdo a realidade dos alunos. (Professor C)

Eu tive formação continuada em outro local que atuei, mas sinto a necessidade de cursos de formação. Meus colegas estão sempre reclamando da dificuldade para compreender os anseios dos discentes e em conseguir fazer com que a aula seja prazerosa para ambos. (Professor D)

Participei de um treinamento em 2010 e foi extremamente tradicional porque não articulou a teoria e prática. (Professor F)

A proposta de trabalho tentou realizar a articulação teórico-prático e entre a ciência e tecnologia. Os docentes foram atuantes e participativos em todo o curso, enquanto interlocutores do processo educacional. Ao exercitarem habilidades docentes em atividades como elaboração de planos de ensino e de instrumentos de avaliação, estudo, aplicação em sala de aula e relato de metodologias e técnicas de ensino que cada participante socializou com o grupo e dele recebeu avaliação e sugestões, foram cooperativos e atuantes, mostraram sua capacidade de reflexão e reconheceram o lugar decisivo e formativo do docente enquanto agente de transformação dos sujeitos. A reflexão internalizada remete que "ensinar não é transferir conhecimento, mas criar as possibilidades para a sua produção ou a sua reconstrução" (Freire, 2006, p. 22).

De acordo com Fullan e Hargreaves (1999), Giesta (2001) e Freire (2006), espera-se que a educação contribua para a formação de um cidadão crítico, reflexivo e transformador de sua realidade; que durante a mediação de conhecimentos e nas práticas reflexivas possa-se perceber que o desenvolvimento docente e discente estão atrelados. Freire (2006) marca na formação permanente dos professores o momento fundamental, que é o da reflexão crítica sobre a prática que "tem de ser de tal modo concreta que quase se confunda com a prática" (p. 39). Ao analisar reflexivamente sua atuação, o docente poderá evidenciar como estão articuladas as suas aulas com os demais processos educativos presentes na vida dos alunos, como afirma Corrêa (2005, p. 133):

Ao se tentar reconhecer os movimentos que permitiram e possibilitam a existência destas sociedades, o professor tenderá a reconhecer cada vez mais, e com maior organizacidade, que suas ações estão articuladas com outros processos educativos, desenvolvidos por outros agentes educadores na sociedade para além da escola, o que, de certa forma, se 
transformará em novas inquietações e renovados desafios para a instituição escolar.

Visualizamos nos excertos dos participantes do curso reflexões sobre o cotidiano escolar, a realidade dos alunos e a participação coletiva na percepção da realidade e no auxílio do processo ensino e aprendizagem, como se pode ver no depoimento do professor D:

Precisamos cada vez mais trazer as empresas para o espaço escolar. Convidá-los para participar na produção dos nossos projetos pedagógicos. Assim, também vamos formar alunos focados para o que o mercado local, regional ou mesmo global, espera.

A formação pedagógica proporcionou aos docentes a reflexão sobre o curso em que atuam, em especial, nos pontos que podem melhorar. Atentou-se para a colaboração da comunidade como um dos fatores que pode vir a auxiliar os docentes a aproximar os conteúdos à realidade concreta dos alunos.

\section{Formação pedagógica enquanto facilitadora do processo ensino e aprendizagem}

A admissão da formação continuada aos docentes enquanto um processo reflexivo facilita a introdução de novos objetivos de ensino e aprendizagem, novas metodologias de ensino e, em especial, na construção de saberes e sentidos que auxiliam na organização do cotidiano escolar.

Giesta (2001), em sua pesquisa acerca do cotidiano escolar e formação reflexiva, reforça a importância de um processo reflexivo e construção de saberes a partir de uma atitude consciente, deliberada e organizada. Ela destaca que

o compromisso com esse papel envolve-o num processo coletivo de reflexão e construção de uma atitude consciente, deliberada e organizada da valorização das situações do trabalho escolar. Isso, no entanto, não pode depender da implantação de um modelo pedagógico externo, ao qual o professor se conforme ou resista. A adoção de uma atitude críticoreflexiva nas situações reais vividas na escola, certamente exigirá dele análise objetiva, bem como, avaliação contínua das formas e conseqüências de sua intervenção pedagógica - individual e coletiva. ( $p$. 38)

Concluímos que o curso de formação facilitou o processo ensino e aprendizagem, por meio dos depoimentos colhidos no decorrer da atividade, pois foi considerado bastante aplicado e serviu de apoio aos docentes durante as aulas ministradas no semestre:

Foi um curso super prático e não segmentado, no qual estávamos envolvidos em todo o processo. Isso facilitou a interação com o conteúdo. Sugiro que os demais professores do Instituto possam participar. Ainda, acho que poderíamos dar continuidade a essa formação com outras temáticas. (Professor A)

Os temas abordados foram atuais, eleitos por nós e, em especial, foram trabalhados de maneira prática. Essa práxis facilita as nossas ações em sala de aula, porque a todo momentos estávamos intercambiando o que aprendemos aqui com o espaço da sala de aula. (Professor C) n. 3 Jan./jun. 2013 p. 7-15 
O curso de formação de professores que foi realizado de forma continuada durante todo o primeiro semestre de 2012 consolidou no âmbito teórico e prático as abordagens e estratégias de ensino. Foi possível socializar experiências vividas, compartilhando dificuldades que enfrentamos na prática em sala de aula e aprimoramos nossas aulas. Discutindo com o grupo descobrimos formas mais interessantes de trabalhar. (Professor E)

Eu gostei muito desse curso, porque ele foi realizado durante o semestre inteiro e não apenas em um final de semana. Assim, pude ir aplicando as técnicas aprendidas, trazendo essa vivência para o grupo e levando alternativas, ideias para melhorar ainda mais as aulas. Aos poucos fomos reinventando as nossas aulas. (Professor F)

Observa-se nos testemunhos dos docentes que a formação continuada não se reduz à aprendizagem de técnicas que os preparem para tarefas específicas e pontuais, mas de buscar superar esse fazer. O espaço da formação serve como qualificação profissional e encontro de discussões pedagógicas que redefinem conceitos no interior da formação docente, pois como expressa Tardif (2008, p. 52):

É através das relações com os pares e, portanto, através do confronto entre os saberes produzidos pela experiência coletiva dos professores que os saberes experienciais adquirem uma certa objetividade: as certezas subjetivas devem ser, então sistematizadas a fim de se transformarem num discurso de experiência capaz de informar ou de formar outros docentes e de fornecer uma resposta a seus problemas.

Ainda, ressalta-se a partir dos depoimentos que há uma necessidade nos Institutos Federais de aperfeiçoamento profissional constante, seja ele desenvolvido por meio de cursos de formação continuada ou pós-graduação, para o pleno exercício do magistério. Reitera-se que a formação do professor não se encerra ao sair da graduação na Universidade, porém continua devendo ocorrer de modo dinâmico e interativo.

\section{Considerações finais}

A formação continuada, por si própria, é uma atividade desafiadora para as instituições de ensino e, tratando-se da formação pedagógica de profissionais de outras áreas, a tarefa constitui-se em um duplo desafio, pois a crença de que o profissional que domina um ofício pode ensiná-lo encontra-se arraigada na educação profissional.

O reconhecimento que a profissão docente exige um conjunto de habilidades que ultrapassa o domínio do saber fazer é um fenômeno tanto recente quanto restrito e, nesse sentido, o grupo de docentes que protagonizou a presente experiência destaca-se pela importância que atribui ao seu fazer cotidiano como profissional da educação.

As reflexões colaborativas surgidas durante o curso repercutiram no fazer cotidiano porque as discussões teóricas foram sendo significadas a partir da prática, o que tornou 0 conteúdo dotado de aplicabilidade, segundo a compreensão dos participantes, corroborando com o que afirma Kuenzer (2002, p. 10):

É preciso considerar que a prática não fala por si mesma; os fatos práticos, ou fenômenos, têm que ser identificados, contados, analisados, interpretados, já que a realidade não se deixa revelar através da observação imediata; é preciso ver além da imediaticidade para compreender as relações, as conexões, as estruturas internas, as formas de organização, as relações entre parte e totalidade, as finalidades, que 
não se deixam conhecer no primeiro momento, quando se percebem apenas os fatos superficiais, aparentes, que ainda não se constituem em conhecimento.

Assim, mais do que simples senso comum, os conhecimentos construídos no exercício profissional pelos professores formam a base sobre a qual significam as teorias, tornando-os relevantes para a sua prática.

\section{Referências}

ARROYO, Miguel. Ofício de mestre: imagens e auto-imagens. Petrópolis: Vozes, 2000.

BUARQUE, Cristovam. A universidade numa encruzilhada. In: UNESCO. Educação superior: reforma, mudança e internacionalização. Brasília: Unesco, 2003, p. 21-74.

CORRÊA, Vera. As relações sociais na escola e a produção da existência do professor. In: FRIGOTTO, Gaudêncio; CIAVATTA, Maria; RAMOS, Marise (orgs.). Ensino médio integrado: concepções e contradições. São Paulo: Cortez, 2005, p.128-147.

FREIRE, Paulo. Pedagogia da autonomia: saberes necessários à prática educativa. São Paulo: Paz e Terra, 2006.

FULLAN, Michel; HARGREAVES, Andy. A escola como organização aprendente: buscando uma educação de qualidade. Porto Alegre: Artes Médicas, 2000.

GIESTA, Nágila C. Cotidiano escolar e formação reflexiva do professor: moda ou valorização do saber docente? Araraquara: JM, 2001.

KUENZER, Acácia Zeneida. Conhecimento e competências no trabalho e na escola. Boletim Técnico do Senac. Rio de Janeiro, v. 28, n. 2, 2002, p. 45-68.

MACHADO, Lucília Regina de Souza. Diferenciais inovadores na formação de professores para a educação profissional. Revista Brasileira da Educação Profissional e Tecnológica. Brasília: MEC/Setec, v. 1, n. 1, 2008, p. 8-22.

OLIVEIRA, Maria Rita Neto Sales de. Formação e profissionalização dos professores do ensino técnico. Educação e Tecnologia, Belo Horizonte, v.11, n. 2, 2006, p. 3-9.

SAVIANI, Dermeval. Os saberes implicados na formação do educador. In: BICUDO, Maria Aparecida Viggiani; SILVA JUNIOR, Celestino Alves da (org.). Formação do educador: dever do estado, tarefa da universidade. São Paulo: Unesp, 1996, p. 145-155.

TARDIF, Maurice. Saberes docentes e formação profissional. Petrópolis: Vozes, 2008.

Ana Sara Castaman é professora no Instituto Federal de Educação, Ciência e Tecnologia do Rio Grande do Sul - campus Sertão.

Endereço: Rodovia RS 135, km 25 - Distrito Englert - 99170-000 - Sertão RS - Brasil.

E-mail: anacastaman@hotmail.com.

Marilandi Maria Mascarello Vieira é professora no Instituto Federal de Educação, Ciência e Tecnologia do Rio Grande do Sul, campus Sertão.

Endereço: Rodovia RS 135, km 25, Distrito Englert - 99170-000 - Sertão RS - Brasil.

E-mail: marilandi.vieira@sertao.ifrs.edu.br.

Recebido em 19 de junho de 2013.

Aceito em 25 de julho de 2013. 